\title{
ASSESSMENT OF LOGISTICS PLATFORM EFFICIENCY USING AN INTEGRATED DELPHI ANALYTIC HIERARCHY PROCESS - DATA ENVELOPMENT ANALYSIS APPROACH: A NOVEL METHODOLOGICAL APPROACH INCLUDING A CASE STUDY IN SLOVENIA
}

\section{Patricija Bajec ${ }^{1}$, Monika Kontelj², Aleš Groznik ${ }^{3}$}

\footnotetext{
1 University of Ljubljana, Faculty of Maritime Studies and Transport, Department of Transport Logistics, Slovenia, ORCID: 0000-0003-1511-1064, patricija.bajec@fpp.uni-lj.si;

2 Mercator d. d., Slovenia, monika.kontelj@t-2.net;

3 University of Ljubljana, Faculty of Economics, Department of Business Informatics and Logistics, Slovenia, ales.groznik@ef.uni-lj.si.
}

\begin{abstract}
The objective of this study is to propose a trustworthy, valid and consistent methodological approach for measuring the efficiency of a logistics platform, where an entire country constitutes a logistic platform. Traditional Data Envelopment Analysis (DEA) is found to be an appropriate tool - if its weaknesses are eliminated. DEA results are highly influenced by the choice of appropriate inputs and outputs variables, but the method itself does not provide guidance for their identification. The authors therefore propose to integrate traditional DEA by combining the Delphi technique with the Analytical Hierarchy Process (AHP) method, which will assist in identifying proper, consistent input/output variables, evaluated by their relevance. The proposed framework allows the performance evaluation of the selected platform's element or elements. It is thus a useful decision support tool for enterprises (private, public, both) that are managing logistics platforms and trying to improve their productivity in order to sustain or improve their position on the competitive market. This methodology allows comparative efficiency analyses to be estimated for similar countries. The presented methodology on one hand enables tailor-made solutions, but on the other hand is very general, and, with minor adjustments, can be applied by a variety of firms and industries. It can be applied in private sector firms in production and service industries, to analyse the relative performance of diverse logistics and non-logistics services, and in public profit or non-profit organisations.
\end{abstract}

Keywords: Supply chain, logistics platform, measuring efficiency, methodology, Delphi, AHP, DEA.

JEL Classification: C39, D57, M21, O49, R42.

APA Style Citation: Bajec, P., Kontelj, M., \& Groznik, A. (2020). Assessment of Logistics Platform Efficiency Using an Integrated Delphi Analytic Hierarchy Process - Data Envelopment Analysis Approach: A Novel Methodological Approach Including a Case Study in Slovenia. E\&M Economics and Management, 23(3), 191-207. https://doi.org/10.15240/tul/001/2020-3-012 


\section{Introduction}

Expanding markets highlight the importance of supply chains as well as logistics management, the effectiveness and efficiency of which rely on an extensive and complex array of interdependent logistics and supply chain issues: services, logistics networks (Bolumole, Closs, \& Rodammer, 2015) and participants in the private and public sectors.

Private sector organisations, mainly bearing responsibility for the cost-effectiveness and agility of the supply chain (Fawcett, Waller, \& Bowersox, 2011), are under constant pressure to respond to new customer requirements. These greatly depend on the quality, accessibility and reliability of logistics networks and their infrastructure.

Public sector organisations, mainly bearing responsibility for logistics networks and their infrastructures, thus face the challenge of planning a more "flexible logistics set-up, based on strategic rather than operational flexibility" (Abrahamsson, Aldin, \& Stahre, 2003). Strategic flexibility requires new logistics structures and organisations, able to follow market changes and, to enhance economic productivity constantly, requires regional growth (Lakshmanan, 2011; Notteboom \& Rodrigue, 2005) and overall regional prosperity.

In response to the current level of dynamism and competitiveness (Silva, Senna, Júnior, Fontes, \& Senna, 2015) and regarding the close relationship, even interdependence, between the supply and logistics chains, the latter has to develop towards logistics platforms. A logistics platform is a very complex venture of organizations (private and public) (Silva et al., 2015) that requires capable leadership able to respond to stakeholders' goals (Sheffi, 2013) and needs. A logistics platform can be, if implemented and managed efficiently, a source of competitive advantage for the region/ country (Antún \& Alarcón, 2014; de Carvalho, de Carvalho, \& Lima Jr, 2013). This implies the necessity for governance and efforts to increase the productivity and efficiency of logistics platforms.

A limited number of studies have directly analysed the productivity of the whole or part of logistics platforms. Articles mostly analyse and propose tools for evaluating just one element of a logistics platform: truck scheduling, infrastructure efficiency, logistics service provider efficiency (Awad-Núñez, González-
Cancelas, Soler-Flores, \& Camarero-Orive, 2015; Gattuso, Cassone, \& Pellicanò, 2014; Srisawat, Kronprasert, \& Arunotayanun, 2017). The efficiency of the logistics platforms was as a whole analysed only by de Carvalho et al. (2013) and by Yang et al. (2017). In both studies, a traditional non-parametric mathematical method, Data Envelopment Analysis (DEA) was used to measure the efficiency of platforms' units. However, both studies lack the critical analysis of DEA concerning logistics platforms characteristics and specifics. It has, therefore, not yet been explored whether DEA is the most reliable and valid modelling technique.

The above mentioned gaps encouraged the authors to perform a more thorough and detailed analysis of the DEA method.

Three research questions (RQ) were developed:

RQ1: Are traditional DEA results feasible and robust enough?

$R Q 2:$ Are the traditional DEA model and its process consistent, transparent and practical enough for logistics platforms' evaluation problems?

RQ3: Which DEA approach, if any, would decrease traditional DEA weaknesses and increase its trustworthiness and validity?

The objectives of this study are twofold. One is the proposal of a trustworthy and valid approach for assessing the efficiency of logistics platforms and highlighting their weakest element or elements. The second is the application of the proposed methodology in a real case study of the Slovenian logistics platform.

\section{Literature Review}

Not many articles have been written on this topic. Most of the articles analyse the efficiency of single logistics platform element. For example, the study of Gattuso et al. (2014) is focused on only the receiving area of a warehouse, as one of the logistics platform's types. The authors introduced a mathematical model for solving a truck scheduling problem in order to increase the performance of one logistics platform element. Srisawat et al. (2017) also focused their research on only one, spatial, aspect of the logistics platform. However, they did develop a 4-stage decision model, integrated by the Analytic Hierarchy Process (AHP) multicriterial method and geographic information system (GIS) technology, for evaluating the spatial 
efficiency of a regional logistics platform. Based on surveys, the list of all logistics platform efficiency indicators, as one of the crucial element of productivity analysis, was presented in this study. Similarly, Awad-Núñez et al. (2015) measured the sustainability of the locations of a dry port, using Multi-Criteria Decision Analysis and Bayesian Networks. Sarmento, Renneboog and Verga-Matos (2017) measured the efficiency of seven highway projects in Portugal. There are numerous studies focused on measuring logistics service providers with different multi-criteria decision making (MCDM) methods (Azadi, Hosseinzadeh Zoroufchi, \& Farzipoor Saen, 2012; Bansal \& Kumar, 2013; Çakir, 2009; Daim, Udbye, \& Balasubramanian, 2012; Qureshi, Kumar, \& Kumar, 2007; Singh, Shankar, Kumar, \& Singh, 2012; Wu \& Yue, 2008; Yasaroglu, Özdağoğlu, \& Özdağoğlu, 2006).

The authors whose research most directly analyse the efficiency of the logistics platform as a whole are de Carvalho et al. (2013). They proposed using a traditional non-parametric mathematical method, Data Envelopment Analysis (DEA), to measure the efficiency of platforms' units. The same method was used by Yang et al. (2017) for analysing the efficiency of Freight Villages. They highlighted the sensitivity of the DEA and therefore propose two solutions: (1) to reduce the error via removal of variables and by jack-knifing and (2) to extend input and output variables. Taking these two proposals and also the advantages of DEA into account, the method is a feasible benchmarking tool. Haralambides and Gujar (2012) were also critical of the selection of inputs/outputs when using DEA for evaluation of dry port efficiency. They argued that the DEA model has so far dealt with only desirable inputs/outputs and failed to address the undesirable $\left(\mathrm{CO}_{2}\right.$ emissions, etc). They, therefore, proposed a new ecoDEA model which evaluates undesirable and desirable outputs of dry ports. MarkovitsSomogyi et al. (2011) highlighted the fact that DEA was widely utilised in the transport sector, but not for analysing the efficiency of distribution centres. After investigating the method and using it in a real case study, they concluded that DEA characteristics are perfect for analysing the distribution centre.

Other studies, listed below, only indirectly relate to logistics platform performance. For example, Yong (2017) analysed the correlations of service innovations capability, delivery system and technology application on the performance of the $\mathrm{O} 2 \mathrm{O}$ platform. A significant positive impact on platform performance was found to exist. Fanti et al. (2017) propose an application of Information and Communications Technology (ICT) tools and the Internet of Things to enhance and simplify collaboration among participants, which further positively influence productivity. Similarly, Cheng and Wang (2016) examine "the potential contributions of a logistics and transport data exchange platform in measuring the performance of supply chain stakeholders of a hub port at different stages along the chain". The same was done by Grzybowska and Gajsek (2016), which demonstrated that the implementation of a common information solution is a step on the way to contemporary and comprehensive logistics platforms.

In summary, there is a lack of studies dealing directly with productivity evaluation in regard to logistics platforms. The traditional DEA was found to be widely used for measuring the efficiency of logistics platform elements, but only twice was applied in cases of logistics platforms. However, this does not make the method itself the only and most reliable modelling technique for evaluating logistics platforms. Only one critical analysis in terms of logistics platforms was made. A comparative analysis of the most commonly used methods was therefore made by the authors, based on the most crucial evaluation criterion, type of results, and several crucial evaluation criteria and principles, proposed by Saaty and Ergu (2015). Measures of central tendency were found to be appropriate to deal with random error and technical efficiency. They are easy to compute and are structured methods. However, they do not identify the most productive units directly. They usually deal with single outputs and require a large number of units. DEA directly identifies the most productive units, enables a ranking of units, deals with multiple inputs and outputs and is structured. The method is sensitive to decision making units, inputs and outputs. Strengths, Weaknesses, Opportunities and Threats (SWOT) enables ranking, invites decision makers to consider important aspects and is able to handle mixed types of data. The method is uncertain, not structured and does not automatically determine weights. The AHP method is able to handle mixed types of data as well as deterministic and non-deterministic 
features of information. The method is structured but requires a pairwise comparison of inputs and outputs. The Technique for Order of Preference by Similarity to Ideal Solution (TOPSIS) is able to handle mixed types of data; it directly identifies the most productive unit, enables ranking, and is structured. However, the method is not able to handle non-deterministic features of information, without extension. Moreover, the method requires the direct rating of inputs/outputs. The ELimination Et Choix Traduisant la Realité (ELECTRE) enables a ranking of units, is able to handle mixed types of data and is structured. However, the method is not able to handle nondeterministic features of information; without extension, it requires a pairwise comparison of inputs/outputs and is complex. The Preference Ranking Organization Method for Enrichment of Evaluations (PROMETHEE) enables a ranking of units, is able to handle mixed types of data and is not complex - but it's time consuming.

All of these methods are subject to a series of limitations. None of the methods, 'despite the existence of a large number of refined methods' (Saaty \& Ergu, 2015), is perfectly suited to any logistics platform efficiency evaluation problems.
These insights, including the fact that DEA was found to be the most commonly used method in multi-criteria analysis of the logistics field in general and the only method applied for productivity measurement of logistics platforms, motivated us to critically analyse whether DEA is the appropriate method to evaluate the efficiency of a logistics platform, to suggest how DEAs weaknesses can be reduced or even eliminated, and to test the proposed methodology.

\section{Methodology}

A three-phase methodological approach is used. Firstly, a detailed DEA analysis was made in terms of utility for assessing logistics platforms. Based on these results, an integrated Delphi-AHP and DEA methodological approach was proposed and then illustrated using a case study of Slovenia in the final phase (Fig.1).

\section{DEA Method}

DEA is a non-parametric linear programming approach for evaluating the relative efficiency of decision-making units (DMUs) (Kocisova, Hass-Symotiuk, \& Kludacz-Alessandri, 2018). The relative performance of an individual DMU is evaluated by comparing it to the most efficient

\section{Fig. 1: Methodological approach}

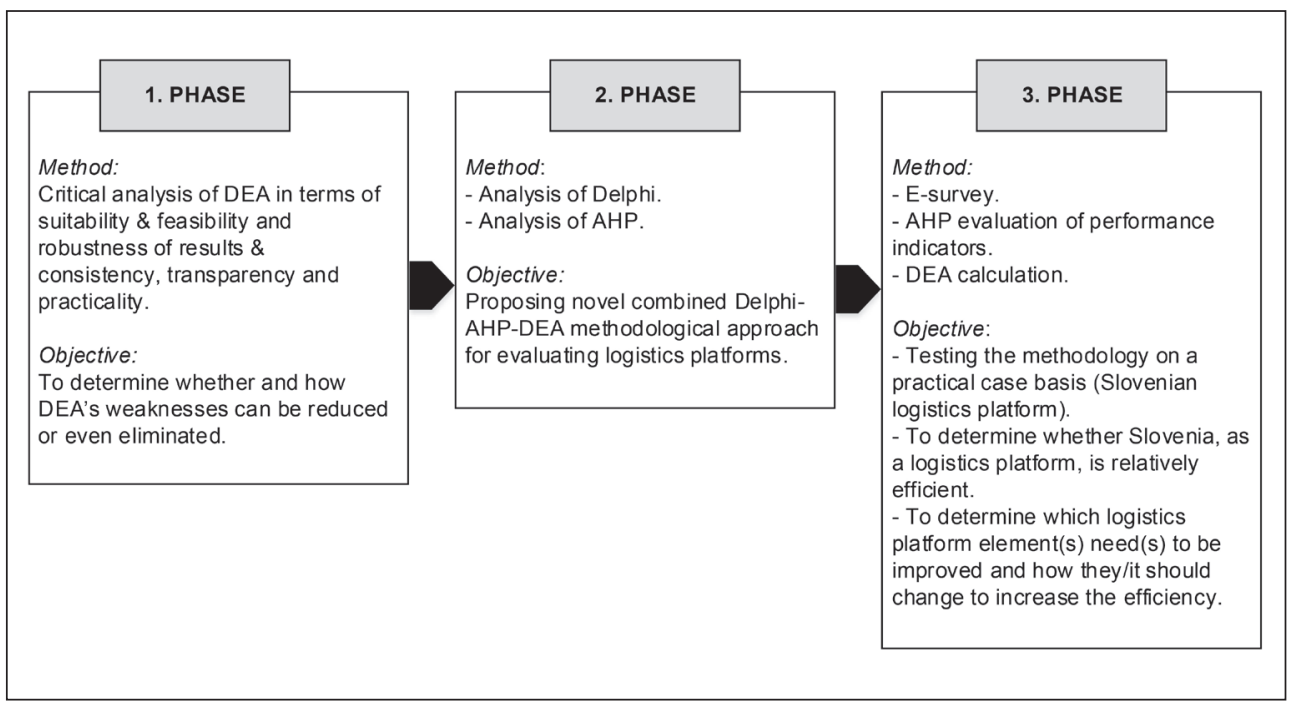


DMU (Haralambides \& Gujar, 2012). The performance measurement, which is shown as an efficiency score, shows the changes in inputs and outputs required in order to reach the most efficient DMU.

\subsection{Basic DEA Models}

Several forms of DEA models were developed. The most widely used are the CCR model and the BCC model. The CCR model, or constant return to scale (CRS), supposes constant return to scale; that is, all DMU are operating at an optimal scale (Yang et al., 2017). The BCC model supposes variable returns to scale (VRS) and does not assume proportionality between inputs and outputs (de Carvalho et al., 2013). Both of the models are input or output oriented. An input oriented model attempts to find the way to minimise the input characteristics of the DMU in order to become efficient. The output oriented model attempts to find the way to maximise the output characteristics to achieve efficiency. Neither the CCR nor BCC model provide enough information for ranking efficient units. A modified model proposed by Cook et al. (1992), Andersen and Petersen (1993) and Dyson et al. (2001) should be applied in this case. The selection of the appropriate DEA model depends on the characteristics of the problem analysed.

All DEA models assume that $n$ DMUs (units) are to be evaluated. Each $D M U_{k}$ $(k=1,2, \ldots, n)$ consumes $m$ different inputs $X_{k}=\left(x_{1 k}, x_{2 k}, \ldots, x_{m k}\right)$ and produces $s$ different outputs $y_{k}=\left(y_{1 k}, y_{2 k}, \ldots, y_{s k}\right)$. The DMU that needs to be measured with the aim of maximizing its efficiency rate is $D M U_{0} . D M U_{0}$ is efficient if the efficiency rate results in a score of 1. However, all weights should be positive and all of the DMUs are to have a lower boundary of 1. Such a model could be defined as:

$$
\begin{aligned}
& \max \frac{\sum_{i=1}^{s} u_{i} y_{i 0}}{\sum_{j=1}^{m} v_{j} x_{i 0}}, \\
& \text { s.t. } \\
& \frac{\sum_{i=1}^{s} u_{i} y_{i k}}{\sum_{i=1}^{k} v_{j} x_{i k}} \leq 1 ; k=1,2, \ldots, n ; \\
& u_{i}, v_{j} \geq \epsilon>0 ; i=1,2, \ldots, s ; j=1,2, \ldots, m ;
\end{aligned}
$$

where $u_{i}$ and $v_{j}$ are weights assigned to $i-t h$ output and $j$ - th input and $\in$ is a small nonArchimedian positive integer.
Model (1) converted to a linear programming format is called a primary CCR model:

s.t.

$$
z_{1}^{*}=\max _{\left\{\mu_{1}, \ldots, \mu_{s}\right\}}\left\{z=\sum_{i=1}^{s} \mu_{i} y_{i 0}\right\}
$$

$$
\begin{aligned}
& \sum_{i=1}^{s} \mu_{i} y_{i \mathrm{k}}-\sum_{j=1}^{m} \omega_{j} x_{j \mathrm{k}} \leq 0 ; k=1,2, \ldots, n ; \\
& \sum_{j=1}^{m} \omega_{j} x_{j 0}=1 ; \\
& \mu_{i}, \omega_{j} \geq 0 i=1,2, \ldots, s ; j=1,2, \ldots, m ;
\end{aligned}
$$

where $u_{i}$ and $v_{j}$ are exchanged to $\mu_{i}$ and $\omega_{j}$ using the Charnes-Cooper transformation.

The equivalent dual model to primary CCR model (2) can be expressed as:

$$
\begin{aligned}
& \text { s.t. } \\
& \sum_{k=1}^{n} x_{j k} \lambda_{k} \leq \theta x_{j 0} ; j=1,2, \ldots m ; \\
& \sum_{k=1}^{n} y_{i k} \lambda_{k} \leq \theta y_{i 0} ; i=1,2, \ldots s ; \\
& \lambda_{k} \geq 0 ; k=1,2, \ldots, n ;
\end{aligned}
$$

where $\lambda=\left(\lambda_{1}, \ldots, \lambda_{n}\right)$ is a vector assigned to individual productive units. This model (3) is also called a 'weak efficiency' model, because it ignores the non-zero slacks (MarkovitsSomogyi et al., 2011).

A non-ignoring non-zero slacks modified model, called an envelopment model, is defined as:

$$
\begin{aligned}
& \quad \theta^{*}=\min \left\{\theta-\varepsilon\left(\sum_{j=1}^{m} s_{j}^{-}+\sum_{i=1}^{s} s_{i}^{+}\right)\right\}, \\
& \text {s.t. } \\
& \sum_{k=1}^{n} x_{j k} \lambda_{k}+s_{j}^{-}=\theta x_{j 0} ; j=1,2, \ldots m ; \\
& \sum_{k=1}^{n} y_{i k} \lambda_{k}-s_{i}^{+}=y_{i 0} ; i=1,2, \ldots s ; \\
& \lambda_{k}, s_{j}^{-}, s_{i}^{+} \geq 0 ; i=1,2, \ldots, s ; j=1,2, \ldots, m ; k=1,2, \ldots, n ;
\end{aligned}
$$

where $\varepsilon$ is a non-Archimedean positive infinitesimal, normally pitched at $10^{-6}$ (Vincová, 2005), and $s_{i}^{-}$and $S_{i}^{+}$are addition input and output variables.

The dual model equivalent to the envelopment CCR model (4), the multiplier model, can be expressed as: 


$$
z_{2}^{*}=\left\{\max z=\sum_{i=1}^{s} \mu_{i} y_{i 0}\right\}
$$

s.t.

$\sum_{i=1}^{s} \mu_{i} y_{i k}-\sum_{j=1}^{m} \omega_{j} x_{j k} \leq 0 ; k=1,2, \ldots, n$;

$\sum_{j=1}^{m} \omega_{j} x_{j 0}=1$

$\mu_{i}, \omega_{j} \geq \varepsilon>0 ; i=1,2, \ldots, s ; j=1,2, \ldots, m$.

Models (3) and (5) are input-oriented CCR models. A $D M U_{0}$ is CCR efficient if the optimum value of the model (4) function equals 1 . In other cases it is inefficient. The lower the value, the less efficient the unit is compared to the rest of the population. This value indicates to what value inputs need to be reduced in order to reach the efficiency of a $D M U_{0}$.

There are also output-oriented CCR models that could be written as follows:

$$
\Phi^{*}=\max \left\{\Phi+\varepsilon\left(\sum_{j=1}^{s} s_{j}^{-}+\sum_{i=1}^{m} s_{i}^{+}\right)\right\}
$$

s.t.

$$
\begin{aligned}
& \sum_{k=1}^{n} x_{j k} \lambda_{k}+s_{j}^{-}=x_{j 0} ; j=1,2, \ldots, m ; \\
& \sum_{k=1}^{n} y_{i k} \lambda_{k}-s_{i}^{+}=\Phi y_{i 0} ; i=1,2, \ldots, s ; \\
& \lambda_{k}, s_{j}^{-}, s_{i}^{+} \geq 0 ; i=1,2, \ldots, s ; j=1,2, \ldots, m ; k=1,2, \ldots, n .
\end{aligned}
$$

$\mathrm{A} D M U_{0}$ is CCR efficient if the optimum value of the model (6) objective function equals 1 . If the value of the objective function is greater than 1 , the unit is inefficient. The variable $\Phi$ shows to what value outputs need to be proportionally increased in order to achieve efficiency.

The models suppose constant return to scale. In order to assume variable return to scale in the DEA BCC model, the additional convexity constraint $\sum_{k=1}^{n} \lambda_{k}=1$ needs to be incorporated into model (4) and (6).

\subsection{Reasons to Use DEA for Logistics Platform Efficiency Assessment}

Firstly, DEA is able to determine the efficiency of a logistics platform's units comprehensively by taking multiple inputs and outputs into account (Hsu, Liao, Yang, \& Chen, 2005). Secondly, DEA enables benchmarking with the best, consistent, logistics platforms. The comparison with best practices reveals potential opportunities for increasing the competitiveness of the logistics platform. DEA not only evaluates the efficiency of the selected unit but also advises, using slack analysis, how to mend its behaviour to reach greater efficiency (Vincová, 2005).

The method, moreover, works in the case of a small sample (Sufian, 2007). This is an important fact in the case of logistics platforms lacking data, difficult and time consuming gathering of data, and even the risk regarding data accuracy. Most of the data is very scattered, difficult to access or even inaccessible.

DEA also automatically determines the weights (Yang et al., 2017) and eliminates the risk of subjective determination of the weights by the user. The weight of each input/output is optimized in order to present each unit in the best possible light (Huguenin, 2012).

The method has a rather low comprehensive structure, since it contains criteria which are not broken into sub-criteria. It involves medium mathematical procedures and meaningful axioms. It is thus medium complicated and can be used if the decision maker puts effort into learning it. However, there are also several software solutions that make the execution even easier.

\subsection{Shortcomings of the DEA Method}

DEA users most often face three problems. First is the selection of the appropriate DEAmodel (Martí, Martín, \& Puertas, 2017), CCR model and BCC model. The requirements of the user and the characteristics of the analysed problem actually dictate the selection of the DEA model. The suitability of the CCR model, which assumes that there is no strong correlation between the size of the DMU and the relative technical efficiency index can be further verified by using the Pearson correlation test (Johnes, 2006).

The second DEA pitfall regards the selection of the appropriate DMUs. The DEA itself does not provide guidance for the selection of the DMUs, but only proposes to "use homogeneous units, able to perform the same tasks with the same goals and to be under the same work conditions of the market" (de Carvalho et al., 2013). Normally, in the benchmark analysis, the selected unit is compared with the best performers, which further means that the DEA is based on extreme points (Vincová, 2005) and is thus sensitive to data and measurement errors.

There is no direct way to test the statistical significance of the DMU from the best- 
performing unit (Kumar Singh \& Kumar Bajpai, 2013). There are several techniques to test the reliability and robustness of the position of the best performing-units: (1) removal of variables and (2) Jack-knifing analysis. In the first analysis one input or output is removed at a time in order to see whether an efficient DMU is still ranked efficient (Ramanathan, 2003; Zhu, 2014). In the second analysis one efficient DMU is removed at a time in order to see the difference of efficiency scores (Charles, Kumar, \& Kavitha, 2012).

As regards the number of DMUs, the rule of thumb proposes to have at least 2 times more DMUs than the sum of the number of inputs and outputs:

nr. of $D M U \geq 2(n r$. of inputs + nr. of outputs $)$

Otherwise the DEA may lose the discriminating power (Tone \& Tsutsui, 2009).

The third and the most problematic DEA difficulty regards the choice of the inputs and outputs. The rule of thumb only suggests the number of DMUs, which further influences the number of inputs/outputs, but does not indicate the ratio between the number of inputs or outputs nor the guidance regarding how to select the relevant inputs and outputs. Past studies thus show that the availability of data (Nataraja \& Johnson, 2011) and suggestions by the authors are still factors that most often assist in identifying inputs and outputs (Bray, Caggiani, \& Ottomanelli, 2015; Rajasekar \& Deo, 2014). This fact, however, raises doubts about the appropriateness of the selected variables and consequently the robustness and reliability of the results. Moreover, valuable information may be lost.

In past studies the Pearson correlation test was used (Rajasekar \& Deo, 2014) for evaluating the robustness of DEA results. In that case, an input/output coefficient below 0.6 in the Pearson correlation test showed that there was no need to eliminate the variable. Otherwise, the input/output needed to be omitted to retain maximum information (Jenkins \& Anderson, 2003). Pastor et al. (2002) proposes using the test with values $\rho=1.1$ and $p_{0}=0.15$ to assess the significance of individual variables and groups of variables. In case the removal of input/output results in a change in efficiency scores which is not substantial, the input/output can be removed. In case the resulting Pastor $p$-values are close to zero, the contribution of input/output is relevant and should not be removed (Johnes, 2006). However, both sensitivity analyses are used when inputs/ outputs are already selected and they therefore do not solve the problem of selecting the right input/output variables.

Aware of their great influence on the final results, the authors believe that this step is most critical and the weakest point of the DEA: but if to some degree ameliorated, the DEA may be the most valid method enabling both the overall efficiency of the logistics platform and the potential for each logistics platform to improve efficiency. The authors therefore suggest applying the traditional DEA method and performing the sensitivity analysis in a similar manner as was used in many past studies in the logistics field, despite the weakest stage of the method, related to inputs-outputs selection. An extension of DEA, adjusted for the logistics platforms' efficiency measurement is introduced in the next section.

\section{Novel Delphi-AHP-DEA Approach}

A two stage-methodological approach is proposed. The first stage (Fig. 2) reduces the risk of improper selection of relevant inputs/ outputs from a large number of indicators significant for the logistics platforms. An integrated Delphi-AHP approach is proposed.

More precisely, the Delphi method is proposed for application for identifying and further evaluating, by applying AHP, the importance of inputs/outputs. A Delphi approach was selected because of the complexity of the elements/indicators of logistics platforms and their correlations, which require appropriate answers and deep understanding of the topic. A sample size of participants in the Delphi process should be large enough - minimum 10 and maximum 30 - participants from sectors which are directly or indirectly most involved in the implementation of the logistics platform and its processes (the public sector, as the owner of the infrastructure, the private sector as the owner and provider of logistics services, and the academic sector and/or consulting companies, mostly involved in the implementation and monitoring processes).

At least two steps need to be conducted. Participants during the first step are asked to identify relevant input and output elements (performance indicators), which in their opinion 


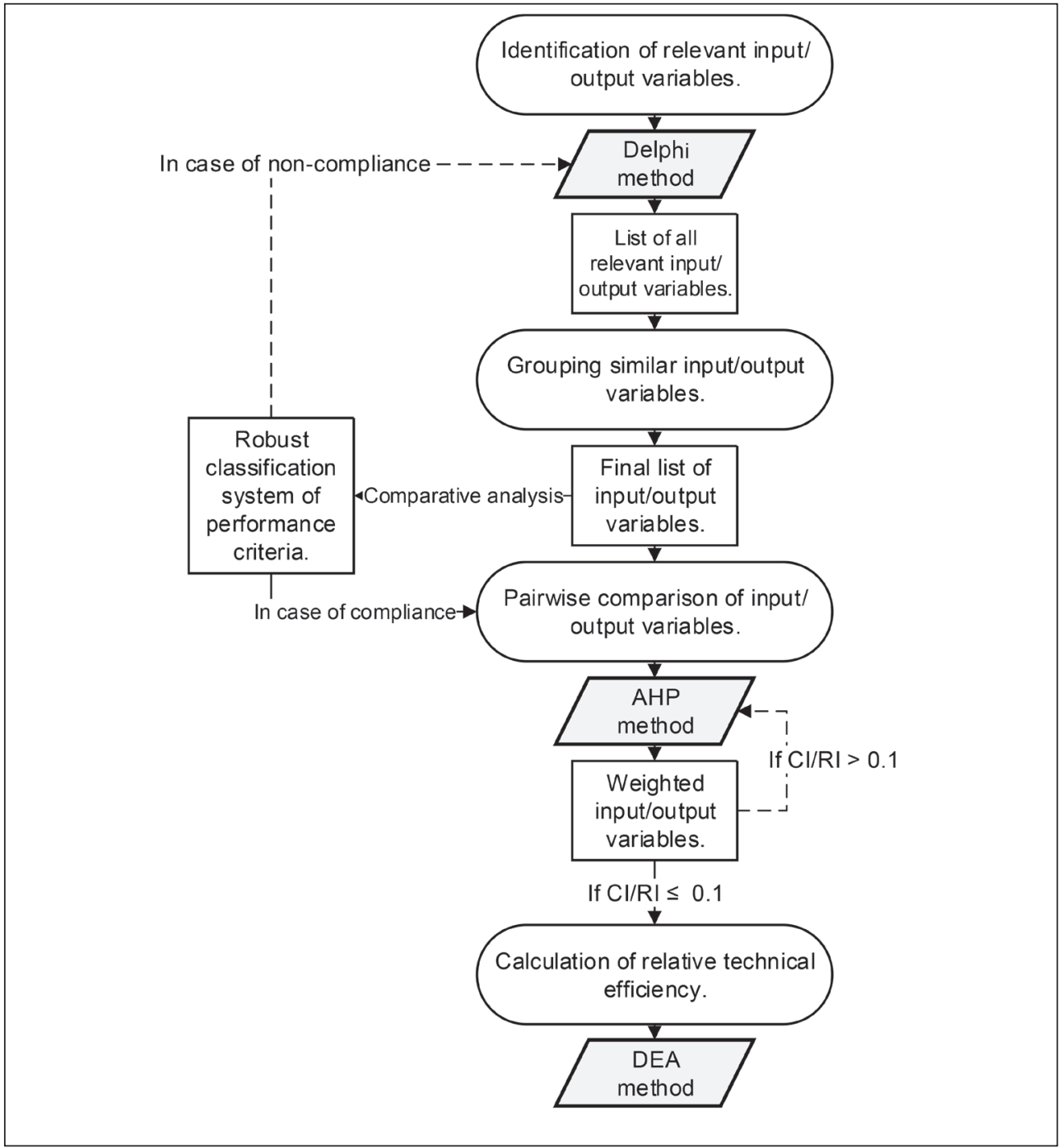

contribute to the efficiency of the logistics platform. Following the first step, data are analysed and then integrated with respect to similarity. To reduce the risk of loss of valuable inputs/outputs, the authors propose comparing the obtained list of indicators with the list of general performance indicators, if they exist. If they do not exist, the authors advise making a systematic review of literature in this field.
In case the comparative analysis shows that some elements were not identified by the participants, they are further asked for reasons and their opinion on this topic. This process can be repeated until consensus regarding the listed elements is reached.

The same list of elements is submitted during the second step back to participants in order that they rank them according to their importance. 
This step is extremely important since not all elements can be included in the DEA analysis because of the decrease of the discriminatory power of DEA when the number of elements increases. It is therefore very important to determine the appropriate elements, which must be identified in a consistent way. In order to satisfy this need for consistency, the authors decided to apply AHP's pairwise comparison of the inputs/outputs.

The AHP method involves four main steps: deconstruction of the decision problem into a hierarchy of interrelated elements, pairwise comparisons of the criteria with 9 degree scale application, calculation of criteria weights and final selection of the right decision (Jaskowski, Biruk, \& Bucon, 2010). During the second step, the decision maker uses a 9 degree Saaty scale and compares each element in a square comparison matrix $A=\left[a_{i j}\right]$ of dimension $n$. The relative weights of criteria $\left(w_{1}, \ldots, w_{n}\right)$ are given by normalizing the Eigen vector $W$ using the arithmetic mean:

$$
w_{i}=\frac{1}{n} \sum_{j=1}^{n} \frac{a_{i j}}{A_{j}} \text { for } \mathrm{i}=1, \ldots, \mathrm{n} ;
$$

where $A_{j}=\sum_{i=1}^{n} a_{i j}$ for $j=1, \ldots, n$. An approximation of the maximum eigenvalue $\lambda_{\max }$ is computed as:

$$
\lambda_{\max }=\sum_{i=1}^{n} A_{i} w_{i} .
$$

On the basis of the characteristics of the comparison matrix, the method consistency can be checked using the consistency index (CI) (Forman, Saaty, Selly, \& Waldron, 1983; Macharis, Springael, De Brucker, \& Verbeke, 2004) defined as:

$$
C I=\frac{\lambda_{\max }-n}{n-1} .
$$

In order to conclude whether the evaluations are consistent, the consistency ratio $(C R)$ is calculated as the ratio of the consistency index $\mathrm{Cl}$ and the random consistency index $\mathrm{Cl}^{*}$ given by Saaty (1990). In the view of Saaty (1990), the inconsistency should not be higher than 10 per cent.

After receiving the pairwise comparison matrix from all participants, the consistency index for each matrix has to be calculated. If $C R$ is satisfactory the decision is taken based on the normalized values; otherwise the matrix is considered again by the participant and this step is repeated till the value lies in a desired range.

After that a geometric mean, which is not significantly affected by fluctuation of sampling and is not affected by extreme values, is used to arrive at a final set of elements. They serve as inputs/outputs for further DEA steps, conducted in the second stage of the proposed methodology (Fig. 3). Three steps and several sensitivity analyses, presented in the flowchart and explained in Sections 3.1 and 3.2, are provided to get to the final answer in regard to relative efficiency.

\section{Case Study}

These sections discuss how the methodology explained above is applied to evaluate the technical productivity of Slovenia as a logistics platform. More precisely, the authors attempt to determine two things: (1) whether Slovenia, as a logistics platform, is relatively efficient and, if it is not efficient (2), which logistics platform's element(s) need(s) to be improved and how they/it should change to increase the efficiency.

\subsection{Identification of Input and Output Variables}

Firstly, e-mail interviews were conducted between September and November 2017 with 13 experts from three different sectors (academic, public and private) which play a crucial role in the implementation and/or the organization of processes of the platform. The following open-ended question was submitted to the experts: Which input/output indicators are, in your opinion, important for the implementation of an efficient logistics platform in Slovenia?

This phase resulted in 39 qualitative and quantitative indicators, which were then, according to similarity integrated into 9 groups: (6 groups of inputs [Tab. 1, $1^{\text {st }}$ column] and 3 groups of outputs [Tab. 1, $3^{\text {rd }}$ column]).

Generally, the inputs are the resources consumed by the logistics platform for several logistics operations and the outputs are results from operations provided on the logistics platform. However, in the present case, the authors attempt to determine the way to improve crucial platform elements to increase the efficiency and therefore the output-oriented DEA approach is the only suitable model. This 


\section{Fig. 3: Flowchart for DEA method implementation}

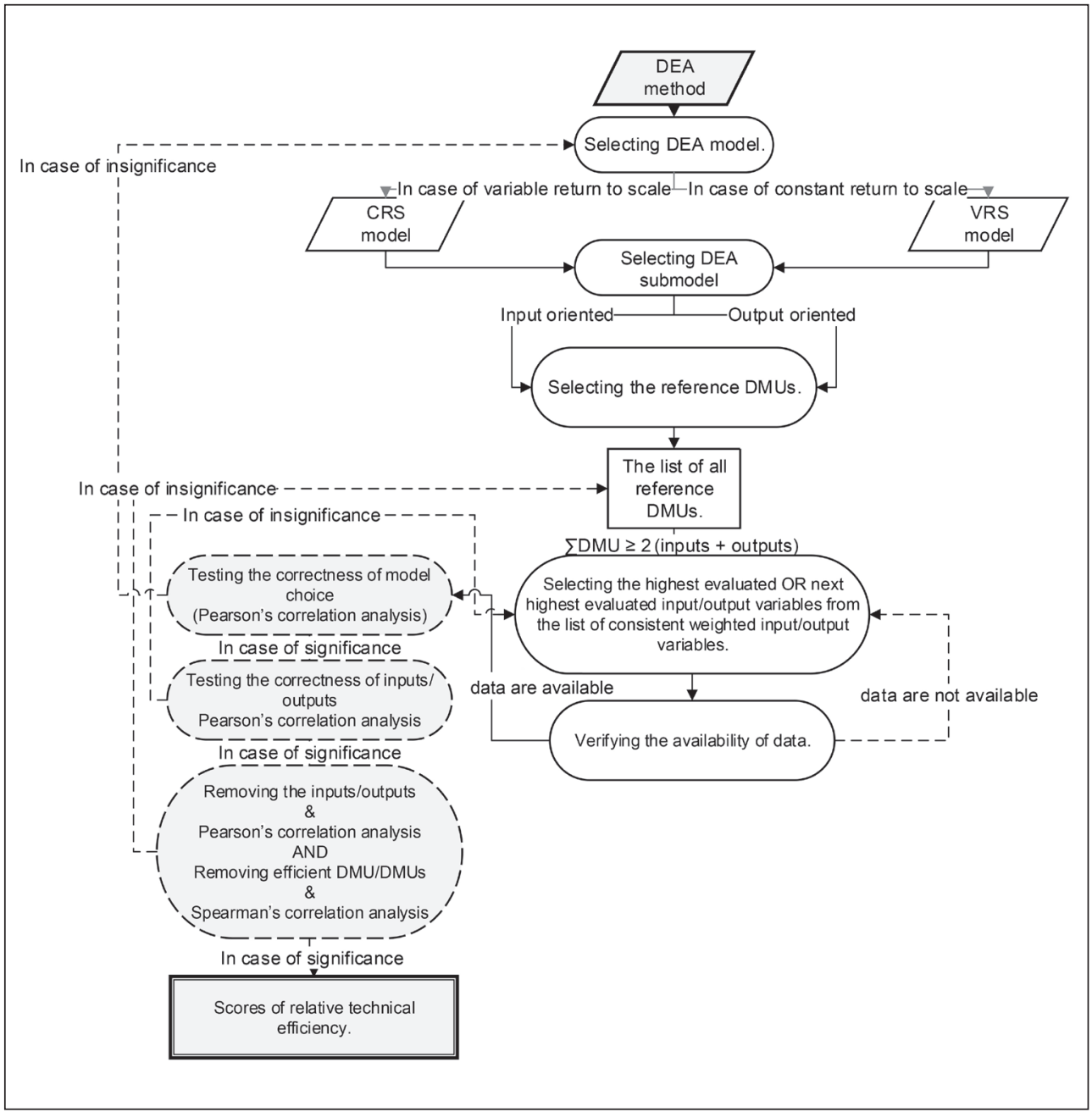

Source: own

model assumes maximisation of outputs by the fixed inputs. Consequently, generally used input elements (see above explanation) in the present case represent output elements and generally used output elements represent input elements.

Since not all inputs and outputs contribute equally to the efficiency of the logistics platform, and in order not to decrease the discriminatory power of the DEA method, a separate pairwise comparison of inputs and outputs is performed in the second phase of interviews by the 7 and not 13 experts (only seven experts responded to the interview). This results in seven input comparison matrices and seven output comparison matrices. In order to confirm the consistency of the experts' evaluations a consistency ratio was calculated. 12 of 14 matrices were consistent. For the inconsistent two the second phase was repeated. When all matrices are consistent, a geometric mean is used to arrive at a final ranking of elements 


\section{Tab. 1: Priority ranking of inputs}

\begin{tabular}{l|c|l|c}
\multicolumn{1}{c|}{$\begin{array}{c}\text { Inputs } \\
\text { (in the present case study } \\
\text { outputs) }\end{array}$} & $\boldsymbol{w}$ & $\begin{array}{c}\text { Outputs } \\
\text { (in the present case study inputs) }\end{array}$ & $\boldsymbol{w}$ \\
\hline Railway infrastructure & $\mathbf{0 . 3 7 3 8 4}$ & Annual goods transhipment & $\mathbf{0 . 6 2 9 4 2}$ \\
\hline Logistics distribution centres & $\mathbf{0 . 1 9 5 0 9}$ & Total gross domestic product (GDP) & $\mathbf{0 . 1 9 9 4 5}$ \\
\cline { 1 - 2 } Modern IT & 0.13503 & $\begin{array}{l}\text { Annual revenue from the logistics } \\
\text { industry }\end{array}$ & 0.17019 \\
\cline { 1 - 2 } Logistics staff & 0.12990 & & \\
\cline { 1 - 2 } Modern suprastructure & 0.11122 & & \\
\cline { 1 - 2 } Administrative support & 0.05492 & &
\end{tabular}

according to their importance (Tab. 1, $2^{\text {nd }}$ column), (Tab. 1, $4^{\text {th }}$ column). Because of the limited number of pages, the AHP analysis results are not displayed.

\subsection{Selecting DMUs}

Taking into account recommendations of the DEA method (homogeneity, ability to perform the same tasks with the same goals, same work conditions) the following European countries, as a reference, were taken: Germany, Belgium, Denmark, Sweden, the Netherlands, Spain, France and potentially Italy. The selected countries are logistics 'superpowers' and have already successfully implemented logistics platforms.

With respect to the rule of thumb (7) only 4 inputs/outputs can be used in the DEA method ( 2 outputs +2 inputs or 3 inputs +1 output or 1 input +3 outputs). The authors decided to include the two most important inputs from the set and the two most important outputs from the set (marked bold in Tab. 1). After that, data collection starts. Combining different sources of data (Eurostat, statistical offices of individual countries, annual financial reports of ports, websites of logistics associations, of single logistics providers, of ministries) the authors managed to collect the necessary data for 2016, since for 2017 it was not yet possible to find all the requested data.

To further confirm whether the selection of input and output data is able to reflect the efficiency of the logistics platform and to verify whether an increase of output will not decrease the input of another item the Pearson's correlation analysis was used (Tab. 2). Although the correlation of the logistics distribution centre and total GDP is moderately significant $(>0.6)$, the authors decided to take it into account because of the small sample size (only 8 countries) and because correlations of others inputs and outputs are less correlated.

\section{Tab. 2: Correlations between variables}

\begin{tabular}{l|c|c|c|c} 
& $\begin{array}{c}\text { Annual goods } \\
\text { transhipment }\end{array}$ & $\begin{array}{c}\text { Total } \\
\text { GDP }\end{array}$ & $\begin{array}{c}\text { Railway } \\
\text { infrastructure }\end{array}$ & $\begin{array}{c}\text { Logistics distri- } \\
\text { bution centres }\end{array}$ \\
\hline Annual goods transhipment & 1 & & & \\
\hline Total GDP & 0.254 & 1 & & \\
\hline Railway infrastructure & 0.228 & 0.156 & 1 & \\
\hline Logistics distribution centres & 0.119 & 0.619 & 0.362 & 1 \\
\hline
\end{tabular}




\subsection{Choice of Orientation and Returns to Scale}

This study employs an output oriented model, since the authors attempt to maximize the outputs (elements of logistics platform) at the input level. Based on the fact that every investment in outputs results in an increase of inputs (investments in infrastructure has positive benefits on the growth of GDP), the CRS model, where constant return to scale is assumed and all DMUs are operating at an optimal scale, seems to be more appropriate. The correlation coefficient between the size of DMU (in our case total annual throughput) and CRS efficiency scores, 0.33 , indicates that here is no correlation between the size of the DMU and efficiency, and so the CRS model proves to be appropriate.

\subsection{Results and Analysis}

The data were evaluated using DEA-Solver by Jablonsky (Jablonský, 2009). Tab. 3 shows the results obtained from the CRS model, which includes a different set of variables in order to evaluate the robustness of the results.

Initially, the DEA is applied to the full data set of 2 outputs and 2 inputs (Tab. 3, $2^{\text {nd }}$ column). The countries that achieved technical coefficient scores equal to 1 are efficient. Coefficient scores higher than 1 display inefficiency. Then, the DEA without one input is applied. Firstly, only the input 'annual goods transhipment' is used (Tab. 3, $3^{\text {rd }}$ column), then just the input 'total GDP' is used (Tab. $3,4^{\text {th }}$ column). At the end, the DEA without one output is applied (Tab. $3,5^{\text {th }}-6^{\text {th }}$ column).

\begin{tabular}{|c|c|c|c|c|c|}
\hline \multirow{2}{*}{\multicolumn{2}{|c|}{ Tab. 3: }} & the full CRS r & and $\mathrm{mc}$ & els without o & \\
\hline & & \multicolumn{2}{|c|}{ Efficiency value without input } & \multicolumn{2}{|c|}{ Efficiency value without output } \\
\hline DMU & $\begin{array}{c}\text { Full CRS } \\
\text { model }\end{array}$ & $\begin{array}{l}\text { Annual goods } \\
\text { transhipment } \\
\text { (in } 1000 \text { tons) }\end{array}$ & $\begin{array}{c}\text { Total GDP } \\
\text { ( } € \text { bill.) }\end{array}$ & $\begin{array}{c}\text { Railway } \\
\text { infrastructure } \\
\text { (in } \mathrm{km} \text { ) }\end{array}$ & $\begin{array}{l}\text { Logistics } \\
\text { distribution } \\
\text { centre } \\
\text { (in } \mathbf{k m}^{2} \text { ) }\end{array}$ \\
\hline Germany & 1 & 1 & 1 & 1 & 1 \\
\hline Belgium & 2.230 & 2.230 & 9.797 & 3.338 & 2.791 \\
\hline Denmark & 1.952 & 1.928 & 5.044 & 2.724 & 2.504 \\
\hline Sweden & 1 & 1 & 1.840 & 2.538 & 1 \\
\hline Netherlands & 3.247 & 3.245 & 25.697 & 3.569 & 5.218 \\
\hline Spain & 1.259 & 1.258 & 2.983 & 4.440 & 1.258 \\
\hline France & 1.150 & 1.523 & 1.407 & 2.449 & 1.150 \\
\hline Slovenia & 2.412 & 7.958 & 2.499 & 130.479 & 2.449 \\
\hline Mean & 1.780 & 2.517 & 6.277 & 18.817 & 2.171 \\
\hline Standard deviation & 0.763 & 2.172 & 7.808 & 42.214 & 1.345 \\
\hline Nr. of efficient DMU & 2 & 2 & 1 & 1 & 2 \\
\hline
\end{tabular}

Germany is efficient in all situations, which shows that its results are robustly efficient and its role as a reference in this model is not questionable. Sweden experiences variation in efficiency scores when variable annual GDP or length of railways is omitted. This indicates that the GDP and length of railways indicators are critical for the efficiency of Sweden. Sweden is therefore marginally efficient.
The Pearson correlation coefficient between the full CRS model and other models presented a range from 0.321 to 0.964 . The results are therefore robust in general.

To test the robustness of the DEA two additional analyses were made. In the first Germany and in the second Sweden was removed from the set of DMUs. Tab. 4 shows that deleting Sweden has as great an impact 


\begin{tabular}{l|c|c|c|c}
$\begin{array}{c}\text { DMU removed } \\
\text { from analysis }\end{array}$ & Mean & $\begin{array}{c}\text { Standard } \\
\text { deviation }\end{array}$ & Nr. of efficient DMUs & $\begin{array}{c}\text { Spearman's correlation } \\
\text { coefficient }\end{array}$ \\
\hline Germany & 1.747 & 0.249 & 2 & 0.757 \\
\hline Sweden & 1.278 & 0.752 & 2 & 0.724 \\
\hline
\end{tabular}

Source: own

\section{Tab. 5: Total output increases needed to make Slovenian logistics platform efficient}

\begin{tabular}{l|c|c|c}
\multicolumn{1}{c|}{ Outputs } & Original value & Virtual value & Difference \\
\hline Railway infrastructure & 1,207 & 2,912 & 1,705 \\
\hline Logistics distribution centre & 1.80 & 231.54 & 229.74 \\
\hline
\end{tabular}

Source: own

as deleting Germany. In the case of removing Germany two countries are efficient; in the case of removing Sweden two countries are efficient as well. Spearman's rank correlation coefficient between the full DMU model and two models with one DMU removed indicated that the coefficients' ranges are significant and the efficiency analysis is stable.

It is worth highlighting that the scores for Slovenia are very low in all modes. Slovenia is therefore far from being efficient. Both outputs 'railway infrastructure' and 'distribution logistics centres' require adjustments. Railway infrastructure requires an increase of $1,705 \mathrm{~km}$ and a logistics distribution centre increase of

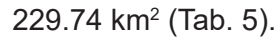

However, Slovenia is not able to build another $1,705 \mathrm{~km}$ of railways due to geographical limitations. The authors therefore calculated the efficiency value as if Slovenia had already built all the railway lines foreseen by Prometni inštitut Ljubljana (2011) (an additional $152 \mathrm{~km}$ of railway lines) (Tab. 6). Slovenia is still inefficient, but its index of relative technical efficiency is lower. These calculations confirm the DEA's possibility of generalizing feedback in order to reflect the real state of a decision and adjust that decision accordingly.

\section{Tab. 6: Efficiency scores for full CRS model, but with additional $152 \mathrm{~km}$ railways lines}

\begin{tabular}{l|c|c}
\multicolumn{1}{c|}{ DMU } & $\begin{array}{c}\text { Full CRS model - present nr. of railway } \\
\text { lines }\end{array}$ & Full CRS model - $\mathbf{1 5 2} \mathbf{~ k m ~ m o r e ~}$ \\
\hline Germany & 1 & 1 \\
\hline Belgium & 2.230 & 2.229 \\
\hline Denmark & 1.952 & 1.952 \\
\hline Sweden & 1 & 1 \\
\hline Netherlands & 3.247 & 3.247 \\
\hline Spain & 1.259 & 1.259 \\
\hline France & 1.150 & 1.150 \\
\hline Slovenia & 2.412 & 2.143 \\
\hline
\end{tabular}




\section{Conclusions}

The development of logistics towards logistics platforms with high strategic flexibility and a design that is a resource base for new market positions is absolutely necessary. This demands a well designed and implemented efficiency monitoring model of logistics platforms.

A combined Delphi-AHP-DEA methodological approach was proposed. The integration of Delphi and AHP enables the identification of the set of inputs/outputs, tailored to the problem undergoing analysis; and, further, determination of their importance. The risk of the most critical step of DEA analysis, is compared to articles published so far, reduced and the results more robust. This partly answers the $R Q 3$.

The integration of Delphi and AHP also enables transparency. The weights for each indicator are endogenously determined to reveal the maximum overall efficiency for each DMU and thus are not subject to specific normative preferences and are also clearly presented and can even be imposed or restricted if necessary. Reproducibility is therefore provided.

The proposed methodology uses the cardinal measurement model with a mathematically logical procedure and axioms and is therefore highly trustworthy (quality method and findings). The methodology generates results that are valid, since they reflect accurately the values of the user, which can also be interpreted via other empirical bases. The results are generally useful for different types of decisions. These facts answer the RQ3.

The DEA conducts several sensitivity analyses to validate the feasibility and robustness of its model and is therefore rated medium feasible and robust (Saaty, 2008). This fact answers the $R Q 1$.

The Delphi-AHP-DEA approach is a structured approach involving several steps, the sequence of which is clearly defined. Each steps' results are either inputs for the next step or trigger the next step. The methodology upgrades theoretical knowledge, but at the same time corresponds to a real situation and thus represents the potential for great support for decision-makers.

The results of the Delphi-AHP-DEA approach can help decision makers understand where the major scope for improvement lies in their country and they may choose to examine why certain countries outperform them and explore whether their peers have adopted policies that are worthy of adoption (Cylus, Papanicolas, \& Smith, 2017). These facts answer the RQ2.

While progress has been made, the proposed framework still leaves some open paths for further improvements and investigation. The authors realised that there is a lack of a solid classification system of performance criteria, involving all sustainable pillars, which serves in the proposed methodology to compare the criteria obtained by the Delphi method. A development of a hierarchytype performance-based model, based on a systematic literature review and international empirical survey, selected MCDM method for criteria evaluation and selection and including sensitivity analysis, such as the Cohen kappa statistics and many others, is required.

A proposed classification system would also be a good basis for the development of the new Delphi-AHP-Slack Based Measure (SBM)DEA model, where not only desirable but also undesirable outputs of logistics platforms, such as $\mathrm{CO}_{2}$ emissions, are taken into account.

The case study illustrated in the article was conducted in only one country, using rather small, but for this case study, the real number of DMUs and a relatively small number of inputs/ output variables. Thus, there are improvements to be made in sample design to allow for further validation and enhancement of the model.

One limiting factor of this study is the rather small number of interviews that were performed. Future studies could expand the sample size.

In the conventional AHP, the pairwise comparison is made using a discrete scale of $1-9$, which is simple and easy to use, but it does not take into account the uncertainty related to the mapping of participants' judgement to a number. The triangular fuzzy numbers, $\tilde{1}$ to $\widetilde{9}$ could be utilized to improve the conventional nine-point scale.

\section{References}

Abrahamsson, M., Aldin, N., \& Stahre, F. (2003). Logistics platforms for improved strategic flexibility. International Journal of Logistics: Research and Applications, 6(3), 85-106. https://doi.org/10.1080/1367556031000123061

Andersen, P., \& Petersen, N. C. (1993). A procedure for ranking efficient units in data envelopment analysis. Management science, 39(10), 1261-1264.

Antún, J. P., \& Alarcón, R. (2014). Ranking Projects of Logistics Platforms: A Methodology Based on the Electre Multicriteria Approach. 
Procedia - Social and Behavioral Sciences, 160, 5-14. https://doi.org/10.1016/j.sbspro.2014. 12.111

Awad-Núñez, S., González-Cancelas, N., Soler-Flores, F., \& Camarero-Orive, A. (2015). How should the sustainability of the location of dry ports be measured? A proposed methodology using Bayesian networks and multi-criteria decision analysis. Transport, 30(3), 312-319. https://doi.org/10.3846/16484142.2015.1081618

Azadi, M., Hosseinzadeh Zoroufchi, K., \& Farzipoor Saen, R. (2012). A combination of Russell model and neutral DEA for 3PL provider selection. International Journal of Productivity and Quality Management, 10(1), 25-39. https://doi.org/10.1504/IJPQM.2012.047940

Bansal, A., \& Kumar, P. (2013). 3PL selection using hybrid model of AHPPROMETHEE. International Journal of Services and Operations Management, 14(3), 373-397. https://doi.org/10.1504/IJSOM.2013.052096

Bolumole, Y. A., Closs, D. J., \& Rodammer, F. A. (2015). The economic development role of regional logistics hubs: a cross-country study of interorganizational governance models. Journal of Business Logistics, 36(2), 182-198. https://doi.org/10.1111/jbl.12088

Bourlakis, M., Melewar, T., Banomyong, R., \& Supatn, N. (2011). Selecting logistics providers in Thailand: a shippers' perspective. European Journal of Marketing, 45(3), 419-437. https://doi.org/10.1108/03090561111107258

Bray, S., Caggiani, L., \& Ottomanelli, M. (2015). Measuring transport systems efficiency under uncertainty by fuzzy sets theory based Data Envelopment Analysis: theoretical and practical comparison with traditional DEA model. Transportation Research Procedia, 5, 186-200. https://doi.org/10.1016/j.trpro.2015.01.005

Çakir, E. (2009). Logistics outsourcing and selection of third party logistics service provider (3PL) via fuzzy AHP (Master Thesis). Bahçeşehir University, Istanbul.

Charles, V., Kumar, M., \& Kavitha, S. I. (2012). Measuring the efficiency of assembled printed circuit boards with undesirable outputs using data envelopment analysis. International Journal of Production Economics, 136(1), 194-206. https://doi.org/10.1016/j.ijpe.2011.11.010

Cheng, M. C. B., \& Wang, J. J. (2016). An integrative approach in measuring hubport supply chain performance: Potential contributions of a logistics and transport data exchange platform. Case Studies on Transport
Policy, 4(2), 150-160. https://doi.org/10.1016/j. cstp.2016.03.001

Cook, W. D., Kress, M., \& Seiford, L. M. (1992). Prioritization models for frontier decision making units in DEA. European Journal of Operational Research, 59(2), 319-323. https://doi.org/10.1016/0377-2217(92)90148-3

Cylus, J., Papanicolas, I., \& Smith, P. C. (2017). Using data envelopment analysis to address the challenges of comparing health system efficiency. Global Policy, 8(52), 60-68. https://doi.org/10.1111/1758-5899.12212

Daim, T. U., Udbye, A., \& Balasubramanian, A. (2012). Use of analytic hierarchy process (AHP) for selection of 3PL providers. Journal of Manufacturing Technology Management, 24(1), 28-51. https://doi.org/10.1108/ 17410381311287472

de Carvalho, C. C., de Carvalho, M. F. H., \& Lima Jr, O. F. (2013). Efficient logistic platform design: the case of Campinas Platform. Paper presented at XVI International Conference on Industrial Engineering and Operations Management, São Carlos, Brazil. Retrieved from http://www.abepro.org.br/biblioteca/ enegep2010_ti_st_113_741_17234.pdf

Dyson, R. G., Allen, R., Camanho, A. S., Podinovski, V. V., Sarrico, C. S., \& Shale, E. A. (2001). Pitfalls and protocols in DEA. European Journal of Operational Research, 132(2), 245-259. https://doi.org/10.1016/S0377-2217 (00)00149-1

Fanti, M. P., lacobellis, G., Mangini, A. M., Precchiazzi, I., \& Ukovich, W. (2017). A flexible platform for intermodal transportation and integrated logistics. Paper presented at the Service Operations and Logistics, and Informatics (SOLI), 2017 IEEE International Conference (pp. 224-229). https://doi. org/10.1109/SOLI.2017.8120998

Fawcett, S. E., Waller, M. A., \& Bowersox, D. J. (2011). Cinderella in the C-suite: conducting influential research to advance the logistics and supply chain disciplines. Journal of Business Logistics, 32(2), 115-121. https://doi.org/10.1111/j.2158-1592.2011.01010.x

Forman, E. H., Saaty, T. L., Selly, M. A., \& Waldron, R. (1983). Expert choice. McLean, VA: Decision Support Software Inc.

Gattuso, D., Cassone, G. C., \& Pellicanò, D. S. (2014). A micro-simulation model for performance evaluation of a logistics platform. Transportation Research Procedia, 3, 574-583. https://doi.org/10.1016/j.trpro.2014.10.036 
Grzybowska, K., \& Gajsek, B. (2016). Supply Chain Logistics Platform as a Supply Chain Coordination Support. In J. Bajo, M. J. Escalona, S. Giroux, P. Hoffa-Dąbrowska, V. Julián, P. Novais, N. Sánchez-Pi, R. Unland \& R. Azambuja-Silveira (Eds.), Highlights of Practical Applications of Scalable Multi-Agent Systems (Vol. 616, pp. 61-72). Cham: Springer. https://doi.org/10.1007/978-3-319-39387-2_6

Haralambides, H., \& Gujar, G. (2012). On balancing supply chain efficiency and environmental impacts: An eco-DEA model applied to the dry port sector of India. Maritime Economics \& Logistics, 14(1), 122-137. https://doi.org/10.1057/mel.2011.19

Hsu, C.-I., Liao, P., Yang, L.-H., \& Chen, Y.-H. (2005). High-tech firm's perception and demand for air cargo logistics services. Journal of the Eastern Asia Society for Transportation Studies, 6, 2868-2880. https://doi.org/10.11175/ easts. 6.2868

Huguenin, J.-M. (2012). Data Envelopment Analysis (DEA): a pedagogical guide for decision makers in the public sector. Chavannes-près-Renens: Institut de hautes études en administration publique.

Jablonský, J. (2009). Software support for multiple criteria decision making problems. Management Information Systems, 4(2), 29-34.

Jaskowski, P., Biruk, S., \& Bucon, R. (2010). Assessing contractor selection criteria weights with fuzzy AHP method application in group decision environment. Automation in construction, 19(2), 120-126. https://doi. org/10.1016/j.autcon.2009.12.014

Jenkins, L., \& Anderson, M. (2003). A multivariate statistical approach to reducing the number of variables in data envelopment analysis. European Journal of Operational Research, 147(1), 51-61. https://doi. org/10.1016/S0377-2217(02)00243-6

Johnes, J. (2006). Data envelopment analysis and its application to the measurement of efficiency in higher education. Economics of Education Review, 25(3), 273-288. https://doi. org/10.1016/j.econedurev.2005.02.005

Kocisova, K., Hass-Symotiuk, M., \& Kludacz-Alessandri, M. (2018). Use of the DEA method to verify the performance model for hospitals. E\&M Economics and Management, 21(4), 125-140. https://dx.doi.org/10.15240/ tul/001/2018-4-009

Kumar, P., \& Singh, R. K. (2012). A fuzzy AHP and TOPSIS methodology to evaluate
3PL in a supply chain. Journal of Modelling in Management, 7(3), 287-303. https://doi. org/10.1108/17465661211283287

Kumar Singh, S., \& Kumar Bajpai, V. (2013). Estimation of operational efficiency and its determinants using DEA: The case of Indian coal-fired power plants. International Journal of Energy Sector Management, 7(4), 409-429. https://doi.org/10.1108/IJESM-03-2013-0009

Lakshmanan, T. R. (2011). The broader economic consequences of transport infrastructure investments. Journal of transport geography, 19(1), 1-12. https://doi.org/10.1016/j. jtrangeo.2010.01.001

Macharis, C., Springael, J., De Brucker, K., \& Verbeke, A. (2004). PROMETHEE and AHP: The design of operational synergies in multicriteria analysis: Strengthening PROMETHEE with ideas of AHP. European Journal of Operational Research, 153(2), 307-317. https://doi. org/10.1016/S0377-2217(03)00153-X

Markovits-Somogyi, R., Gecse, G., \& Bokor, Z. (2011). Basic efficiency measurement of Hungarian logistics centres using data envelopment analysis. Periodica Polytechnica Social and Management Sciences, 19(2), 97-101. https://doi.org/10.3311/pp.so.2011-2.06

Martí, L., Martín, J. C., \& Puertas, R. (2017). A DEA-LOGISTICS PERFORMANCE INDEX. Journal of Applied Economics, 20(1), 169-192. https://doi.org/10.1016/S1514-0326(17)30008-9

Matajič, M., Šarenac, M., Bolha, V., Dobrijević, A., Fridrih Praznik, M., Genjac, A., ... Kramar, U. (2011). Analiza možnosti in potreb razvoja javne železniške infrastrukture $v$ Republiki Sloveniji: Strokovno-razvojna naloga, končno poročilo. Ljubljana: Prometni inštitut Ljubljana.

Nataraja, N. R., \& Johnson, A. L. (2011). Guidelines for using variable selection techniques in data envelopment analysis. European Journal of Operational Research, 215(3), 662-669. https://doi.org/10.1016/j.ejor.2011.06.045

Notteboom, T. E., \& Rodrigue, J.-P. (2005). Port regionalization: towards a new phase in port development. Maritime Policy \& Management, 32(3), 297-313. https://doi. org/10.1080/03088830500139885

Pastor, J. T., Ruiz, J. L., \& Sirvent, I. (2002). A statistical test for nested radial DEA models. Operations Research, 50(4), 728-735. https://doi.org/10.1287/opre.50.4.728.2866

Qureshi, M., Kumar, D., \& Kumar, P. (2007). Selection of potential 3PL services 
providers using TOPSIS with interval data. Paper presented at the Industrial Engineering and Engineering Management, 2007 IEEE International Conference (pp. 1512-1516). https://doi.org/10.1109/IEEM.2007.4419445

Rajasekar, T., \& Deo, M. (2014). Is there any efficiency difference between input and output oriented DEA Models: An approach to major ports in India. Journal of Business and Economic Policy, 1(2), 18-28.

Ramanathan, R. (2003). An introduction to data envelopment analysis: a tool for performance measurement. New Delhi: Sage Publications.

Saaty, T. L. (1990). How to make a decision: The analytic hierarchy process. European Journal of Operational Research, 48(1), 9-26. http://dx.doi.org/10.1016/03772217(90)90057-I

Saaty, T. L. (2008). Relative measurement and its generalization in decision making why pairwise comparisons are central in mathematics for the measurement of intangible factors the analytic hierarchy/network process. RACSAM - Revista de la Real Academia de Ciencias Exactas, Fisicas y Naturales. Serie A. Matematicas, 102(2), 251-318. https://doi. org/10.1007/BF03191825

Saaty, T. L., \& Ergu, D. (2015). When is a decision-making method trustworthy? Criteria for evaluating multi-criteria decisionmaking methods. International Journal of Information Technology \& Decision Making, 14(06), 1171-1187. https://doi.org/10.1142/ S021962201550025X

Sarmento, J., Renneboog, L., \& VergaMatos, P. (2017). Measuring highway efficiency by a DEA approach and the Malmquist index. European Journal of Transport and Infrastructure Research, 17(4), 530-551. https://doi.org/10.18757/ejtir.2017.17.4.3213

Sheffi, Y. (2013). Logistics-intensive clusters: global competitiveness and regional growth. In Handbook of global logistics (pp. 463-500). New York, NY: Springer.

Silva, R. M. d., Senna, E. T. P., Lima, O. F. Jr, \& Senna, L. A. d. S. (2015). A framework of performance indicators used in the governance of logistics platforms: the multiple-case study. Journal of Transport Literature, 9(1), 5-9. https://doi.org/10.1590/2238-1031.jtl.v9n1a1
Srisawat, P., Kronprasert, N., \& Arunotayanun, K. (2017). Development of decision support system for evaluating spatial efficiency of regional transport logistics. Transportation Research Procedia, 25, 48324851. https://doi.org/10.1016/j.trpro.2017.05.493

Sufian, F. (2007). Trends in the efficiency of Singapore's commercial banking groups: A non-stochastic frontier DEA window analysis approach. International Journal of Productivity and Performance Management, 56(2), 99-136. https://doi.org/10.1108/17410400710722626

Tone, K., \& Tsutsui, M. (2009). Network DEA: A slacks-based measure approach. European Journal of Operational Research, 197(1), 243-252. https://doi.org/10.1016/j.ejor. 2008.05.027

Vincová, K. (2005). Using DEA models to measure efficiency. Biatec, 13(8), 24-28.

Wu, H.-b., \& Yue, Y. (2008). 3PL Vendors Evaluation Project Based on Entropy Right TOPSIS. Journal of Lanzhou Jiaotong University, 27, 88-91.

Yang, C., Taudes, A., \& Dong, G. (2017). Efficiency analysis of European Freight Villages: three peers for benchmarking. Central European Journal of Operations Research, 25(1), 91-122. https://doi.org/10.1007/s10100015-0424-5

Yasaroglu, B. A., Özdağoğlu, G., \& Özdağoğlu, A. (2006). Fuzzy logic-based decision making model on selection and evaluation of logistics service providers within a firm. Paper presented at the 4th International Logistics and Supply Chain Congress, Izmir, Turkey.

Yong, G. (2017). The Impact of Service Innovation Capability on Logistics Platform Performance. Paper presented at International Conference on Economics, Management Engineering and Marketing (EMEM 2017). https://doi.org/10.12783/dtem/emem2017/17098

Zhu, J. (2014). Quantitative models for performance evaluation and benchmarking: Data envelopment analysis with spreadsheets, In International Series in Operations Research \& Management Science (Vol. 213). Cham: Springer. https://doi.org/10.1007/978-3-31906647-9 